Dr. F. L. van Muiswinkel:

\section{DE HANDELSONDERNEMING}

N.V. Noord-Hollandse Uitgevers Mij, Amsterdam 1959, XI en $258 \mathrm{blz}$.

$$
\text { door Prof. Dr. J. L. Mey }
$$

Dit boek is te beschouwen als een vervolg op het eerder van de hand van deze schrijver verschenen werk, Handel, Markt en Beurs. Toch heeft de auteur het een ander karakter willen geven. Terwijl Handel, Markt en Beurs een beschrijving en verklaring wil geven van de structuur van de handel als deel van het maatschappelijk produktieproces, houdt De Handelsonderneming zich bezig met de bijzondere problematiek van de categorie bedrijfshuishoudingen, die zich op het vervullen van de handelsfunctie hebben verbijzonderd. Het is duidelijk, dat zo gezien beide delen los van elkaar staan; het eerste behoort naast overeenkomstige werken over geld en bankwezen, transportwezen e.d.m. tot de algemene economie, in het tweede daarentegen wil de schrijver de bijzondere bedrijfseconomie van een tot een bepaalde groep behorende categorie van ondernemingen behandelen. Hij volgt hierbij dus een beginsel, dat in de duitse „Betriebswirtschaftslehre” gebruikelijk is. Daar te lande toch is de bedrijfshuishoudkunde in sterke mate gespecialiseerd naar bedrijfstak en niet zelden treft men dan ook in de universiteiten en hogescholen afzonderlijke leerstoelen aan voor Industriebetriebslehre, Handelsbetriebslehre, Bankbetriebslehre e.d.

Naar hier te lande heersende opvattingen is een dergelijke specialisatic niet noodzakelijk, ja zelfs ongewenst. De bedrijfseconomische problematiek zou in het algemeen voor alle categorieën van bedrijfshuishoudingen dezelfde zijn; wel vertonen de problemen verschillen, al naar gelang ze op het gebied van de calculatie, de financiering of de organisatie liggen. Meer reden dan voor een specialisatie in de beoefening der bedrijfseconomie naar de bedrijfstak is er grond voor een differentiatie naar bovengenoemde functionele gebieden.

De vraag kan dus worden gesteld, keert de schrijver zich principieel tegen de heersende opvattingen in ons land en is dit werk een poging om tot een meer gespecialiseerde beoefening der bedrijfshuishoudkunde, zoals die elders gebruikelijk is, te komen.

$\mathrm{Na}$ kennisname van dit boek moet deze vraag naar ik meen ontkennend worden beantwoord. Wat naar onze indruk de bedoeling van de schrijver en tegelijk de betekenis van zijn werk is zal uit het hiernavolgende blijken.

De structuur van het boek is aldus, dat de schrijver eerst zijn aandacht schenkt aan de vorm van het handelsbedrijf, daarna worden het kostenprobleem en het financieringsprobleem aan de orde gesteld. Hiermee wordt $\operatorname{deel} A$, bedrijfsvorm en beheer, van het werk afgesloten.

Deel $B$ behandelt vestigingsplaats en bezetting van het distributieapparaat en voorts mededingingsregelingen en publiekrechtelijke bedrijfsorganisatie.

In deel $\mathrm{C}$ worden dan een aantal differentiaties in de bedrijfskolom besproken als het veembedrijf, het vervoerbedrijf en het assurantiebedrïf.

Een bijlage gecft daarna een aantal informatiebronnen voor de handel als Centraal Bureau voor de Statistiek, Economische Voorlichtingsdienst, Economisch Instituut voor de Middenstand, Kamers van Koophandel, e.d.

Men zou vanuit schrijvers eigen doelstelling tegen deze structuur wel enige bedenkingen kunnen aanvoeren. In de eerste plaats kan men zich afvragen waarom het vestigingsplaatsprobleem niet onder de bedrijfseconomische problematiek, die de schrijver in de ecrste afdeling wenst te behandelen, had kunnen worden gerangschikt. Wat verder in dit deel van het boek wordt behandeld raakt maar ten dele de specifieke problematiek van de handelsonderneming. Het valt evenzeer slechts ten dele tot de bedrijfseconomische problematiek te rekenen.

Wat deel $\mathrm{C}$ aangaat, we zouden het liever een plaats hebben gegund in van Muiswinkel's eerste boek, dat een in hoofdzaak institutionele behandeling van de handelsgeledingen der maatschappelijke voortbrenging bevat. Immers het gaat hier om bepaalde differentiaties in de bedrijfskolom, die op zich zelf nog geen differentiaties binnen de handelsgeleding behoeven te zijn, al zullen ze daar veelvuldig optreden.

Uiteraard zijn dit tot op zekere hoogte persoonlijke preferenties, zij behoeven geen afbreuk te doen aan de verdiensten van dit werk. Schrijvers werk zou wel aan gaafheid van conceptie gewonnen hebben, indien hij zich inderdaad tot de bedrijfseconomische problemen van de handelsonderneming had 
beperkt. Waar de schrijver zelf de behandeling van deze problemen als de hoofdzaak van de door hem ondernomen taak beschouwt wordt hem in ieder geval geen groot onrecht aangedaan als de beoordelaar zich wel de beperking oplegt dic hij van de schrijver had verwacht. Dit betekent dus een beperking tot deel $\mathrm{A}$ en een gedeelte van deel $\mathrm{B}$.

De eerste hoofdstukken van deel A zijn beschrijvend. Achtereenvolgens worden na een inleiding (hoofdstuk I), de groothandelsbedrijven (hoofdstuk II) en de detailhandelsbedrijven (hoofdstuk III) behandeld. Interessant zijn in het tweede hoofdstuk de gegevens over de moderne groothandel in vergelijking met de groothandel in vroeger eeuwen. Uiteraard moest de schrijver zich hier beperken wilde hij het doel dat hij met dit boek beoogde, nl. het schrijven van een tekstboek voor studenten, niet voorbijschieten. Het is niettemin jammer, dat op de geconstateerde verschillen tussen heden en verleden, afgezien van enkele summiere opmerkingen nauwelijks wordt ingegaan. Hetzelfde is ook het geval, en hier is het minder begrijpelijk, met de behandeling van de groothandel in grondstoffen en de groothandel in cindprodukten, een onderscheiding die voor een groor deel parallel loopt met die in collecterende en distribuerende groothandel. Zo zou men ook nog kunnen onderscheiden tussen de voorraadvormende groothandel en de niet-voorraadvormende, verplaatsende, groothandel. Hiermee zijn we nog niet aan het eind van een opsomming van de bedrijfsvormen in de groothandel, maar verder behoeft niet te worden gegaan om te constateren dat, hoezeer van Muiswinkel gelijk heeft als hij zegt dat de bedrijfsvormen in de groothandel minder talrijk zijn dan in de detailhandel, hij van de vormen van groothandelsbedrijf toch wel een te geringe indruk geeft. In het derde hoofdstuk wordt een verdienstelijke beschrijving gegeven van verschillende vormen van detailhandel. Evenals bij de distribuerende groothandel geeft van Muiswinkel van de meeste dezer bedrijven een inzicht in de kosten in grootte en samenstelling, de omzet, de omzetsnelheid, de brutowinst en het economisch resultaat. Het is bijzonder interessant deze grootheden van de verschillende bedrijfstypen met elkaar te vergelijken. Het is jammer dat deze gegevens, zoals ze door de schrijver worden geproduceerd, niet altijd gemakkelijk vergelijkbaar zijn. Soms ontbreken ze ook. Bovendien zou men van de op dit gebied bijzonder deskundige auteur gaarne een wat meer analyserende beschouwing van de geconstateerde differenties hebben gezien.
Terecht legt van Muiswinkel bij de ontwikkeling van de verschillende nieuwe vormen van detailhandel de nadruk op de parallelisatie. De oorzaken voor het streven naar parallelisatie en van het succes daarvan worden slechts ten dele aangestipt. We zouden gaarne gezien hebben, dat de schrijver zich verder had verdiept in de in ons huidig economisch bestel liggende oorzaken voor het genoemde verschijnsel. Misschien acht de schrijver dat wat veel gevergd voor het doel dat hij heeft beoogd. Niettemin lijkt het ons dat juist op dit gebied, waar de ontwikkeling zoals van Muiswinkel terecht opmerkt ,zeker even spectaculair is als op het gebied van de technische produktie" een dieper ingaan op de problematiek van die ontwikkeling door iemand met zijn ervaring uiterst waardevol zou zijn geweest.

Bij de behandeling van het kostenprobleem vraagt de schrijver zich af of een verantwoorde calculatie in de handel mogelijk is. Hocwel hij deze vraag bevestigend beantwoordt acht hij voor het handelsbedrijf een eigen methode van kostprijscalculatie noodzakelijk. Dit zal dan een methode moeten zijn waarbij de normale produktie-omvang geen rol speelt. Verder zal men bij een dergelijke methode moeten bedenken "dat én de onvermijdelijke overcapaciteit én het constante karakter der exploitatiekosten een situatie scheppen, waarbij geen causaal verband meer is te leggen tussen de totale capaciteitskosten en de individuele artikelen."

Het wil ons voorkomen dat van Muiswinkel hier zeer juist de principiële moeilijkheden van de kostprijsberekening in de handel heeft gesignaleerd. Deze moeilijkheden hangen trouwens met elkaar samen en culmineren in de bepaling van de normale bedrijfsbezetting. Ze schuilen niet in de veelheid van artikelen, die door de handel worden gevoerd, hoewel van Muiswinkel aan dit argument toch blijkens een voorafgaande passage in zijn werk wel waarde schijnt te hechten (blz. 68).

Tegenover de veelheid van artikelen staat gewoonlijk de beperktheid der verrichtingen, die door de handel, in tegenstelling tot vele industriële processen, worden uitgevoerd.

De moeilijkheid schuilt op zich zelf ook niet in de onderlinge verbondenheid der artikelen. Ook hicraan blijkt van Muiswinkel een niet onbelangrijke waarde toe te kennen. Immers „wanneer het mogelijk zou blijken om de totale exploitatiekosten wel te verbijzonderen, dan nog zou men niet voorbij mogen gaan aan het feit dat het aanbieden van éen bepaald artikel tevens de verkoop 
van de rest van het assortiment stimuleert" (blz. 78). Zou van Muiswinkel hieruit een consequentie willen trekken voor het vraagstuk van de verbijzondering der kosten, dan zou dit geen andere kunnen zijn dan dat alle kosten met inbegrip van de bij de inkoop betaalde prijzen geacht moeten worden voor het gehele assortiment te zijn gemaakt. Er zou dan zelfs geen aanleiding zijn de inkoopbedragen aan de individuele artikelen toe te rekenen. Ook de in de praktijk gangbare methode zou men dan niet ,ook wetenschappelijk als de meest juiste" (blz. 79) mogen accepteren.

Als men bovendien iets verder wil komen met de variatie in bruto-winstopslagen dan alleen hẹt intuïtief bepalen daarvan zal men toch weer moeten rekenen. Eigenlijk komt men er dan toe en dat lijkt mij ook de meest juiste weg, een prijs voor de opslag van de goederen vast te stellen, welke varieert met de mate waarin de goederen van de beschikbare opslagcapaciteit gebruik gemaakt hebben. Ditzelfde warc ook te doen voor de overige verrichtingen die de handel pleegt uit te vocren als het ompakken, het transporteren, e.d.

De verbondenheid in de zin van gemeenschappelijkheid kan men strikt genomen alleen, althans meestal, volhouden bij de kosten van de eigenlijke verkoop. Hier is inderdaad de band met het individuele artikel gewoonlijk verbroken. De vertegenwoordiger verkoopt hier veelal in een en dezelfde handeling meer artikelen. Zelfs behoeft er geen aanwijsbaar verband te bestaan tussen zijn bezoeken en de individuele bestellingen, zodat deze kosten zelfs niet per order verbijzonderbaar zijn.

Wij menen dus dat als men een oplossing zou kunnen vinden voor de bepaling van de normale bedrijfsbezetting althans een groot deel van de kosten die thans door de brutowinstmarge moeten worden gedekt wel toerekenbaar zouden zijn. Zonder hierop nu te dezer plaatse verder in te gaan lijkt ons dit vraagstuk niet geheel onoplosbaar toe, zeker niet als men het handelsbedrijf splitst naar de categorieën van verrichtingen, die daar worden uitgevoerd en die als het ware als kostenplaatsen zijn te beschouwen.

Wij geloven bovendien dat een nader onderzoek naar de mogelijkheden van kostenverbijzondering in de handel zijn nut heeft, al zou het alleen maar zijn ten behoeve van een critische beoordeling van de gebruikelijke marges.

Een boekbespreking kan niet teveel ruimte in beslag nemen. Niet alle onderdelen van dit werk kunnen dan ook even uitvoerig besproken worden.

Het gedeelte handelend over de financiering van de handelsonderneming beoogt kennelijk en voornamelijk de overdracht van institutionele kennis aangaande wijze van financiering. Het is als zodanig zeer verdienstelijk, niet het minst door de feitelijke gegevens die ter illustratie van het betoog zijn bijeengebracht.

We zouden het echter hebben toegejuicht indien de schrijver toch wat meer analyserende beschouwingen in zijn werk had opgenomen.

De vraag is voorts bij mij gerezen of de beschrijving van het verloop van een exporttransactie eigenlijk niet eerder in Handel, Markt en Beurs zou thuishoren. Men kan deze credieten wel in het kader van de bedrijfseconomie behandelen, maar dan moet dit op een andere wijze geschieden dan de schrijver gedaan heeft.

Eenzelfde opmerking geldt trouwens ook voor andere gedeelten van dit werk, zoals wij reeds hebben opgemerkt.

Ook over de vestigingsplaats van de handel en bezetting van het distributieapparaat geeft van Muiswinkel lezenswaardige beschouwingen. $\mathrm{Bij}$ dit laatste vraagstuk - afgezien of het nog tot de bedrijfseconomie van de handelsonderneming behoort - valt het op dat in het bijzonder bij de bespreking van de kleinhandelsgeleding niets gezegd wordt over de "retail-trade mortability" en zijn consequenties.

Onze beoordeling afsluitend kunnen we zeggen dat ondanks het critisch geluid dat we hebben laten horen de lezing van dit boek voor ons waardevol is geweest. Wij verwachten dat dit ook voor de gebruikers het geval zal zijn. Niet in het minst is dat naar onze mening te danken aan de grondige kennis die de schrijver bezit van de onderwerpen, die hij heeft behandeld, en die hem ongetwijfeld in staat doet zijn ook aan onze be$z$ waren bij een volgende druk, die waarschijnlijk wel niet lang op zich zal laten wachten, tegemoet te komen voorzover hij zulks dienstig acht. 
Th. J. Steenbergen:

\section{DE INVLOED VAN DE AUTOMATISE- RING OP HET BEDRIJF}

Een studie aan de hand van gegevens omtrent de automatisering in Amerikaanse bedrijven. Serie Bedrijfseconomische monographieën XXVIII.

(Stenfert Krocse; Leiden) 1960. 175 p.

\section{door A. B. Frielink}

Deze studie is eerder verschenen als academisch proefschrift ter verkrijging van de graad van doctor in de Economische wetenschappen aan de Universiteit van Amsterdam, in het openbaar verdedigd op 10 juni 1960.

$\mathrm{Zij}$ vormt een pendant van het bij dezelfde uitgever en eveneens eerder als academisch proefschrift (1958) verschenen „Enkele sociaal-economische gevolgen van de automatie" door J. Bosch. Uitdrukkelijk wordt hier gesproken van een en niet van het pendant, omdat met deze beide werken het gehele economische terrein dat door de automatisering wordt beïnvloed, nog aiec is betreden, hoezeer de beide titels in samenhang bezien, dit mogen suggereren.

In tegenstelling tot wat de titel „De invloed van de automatisering op het bedrijf" zou doen verwachten, indien deze verschijnt in een serie Bedrijfseconomische monographieën, behandelt Steenbergen veel meer de bedrijfssociologische en bedrijfspsychologische aspecten van de automatisering, dan de bedrijfseconomische. Het is duidelijk dat de leer van de interne organisatie het niet zonder deze sociologische/psychologische basis af kan, zodat bedoelde aspecten ook voor de bedrijfseconoom van uitermate groot belang zijn. Pas indien hun studie zou leiden tot normatieve conclusies ten aanzien van dc criteria die bij een keuze van een organisatievorm moeten worden aangelegd, zou gesproken kunnen worden van een bedrijfseconomische studie, waarbij dan aan aspecten als invloed van de automatisering op de kostprijs, op de financiering van de bedrijfshuishouding, op de resultaatbepaling, op de administratie e.d., eveneens aandacht had moeten zijn geschonken.

Dit is uiteraard geen verwijt tegen de inhoud van het boek van Steenbergen, doch meer een stimulans voor volgende promovendi: onder dezelfde titel kunnen nog enkele dissertaties met volkomen verschillende inhoud geschreven worden.
Wic de studie van Steenbergen onbevangen hceft gelezen, moet wel een beeld van de toekomst krijgen dat overeenstemt met hetgeen de schrijvers van semi-wetenschappelijke toekomstverhalen ons op zijn naargeestigst hebben voorgespiegeld. Als men de consequenties doordenkt van een zin als „Het gevolg hiervan zal zijn, dat de creatieve functies steeds meer bij de topleiding komen tc berusten" (p. 75) komt al spoedig terecht bij George Orwell's 1984. En het op dezelfde bladzijde even later opgenomen:

„Automatisering ontsluit echter het tijdperk van de ongewone mens, het buitenbeentje, de intellectueel met vreemde doch waardevolle ideeën" zal diegenen onder ons die zich niet tot de „buitenbeentjes” rekenen, weinig geruststelling geven.

Deze suggestie, die van het boek als geheel uitgaat, doch die bepaald niet expliciet wordt gesteld en waarschijnlijk door Steenbergen evenmin wordt bedoeld, is een gevolg van twee omstandigheden.

a. De gekozen definitie;

b. Het feit dat in de studie slechts één begrenzing wordt gegeven van het roepassingsgebied van automatisering.

Uit hoofde van beide omstandigheden is het nuttig het hier besproken boek te confronteren aan de eerder genoemde dissertatic van J. Bosch. Laat ons eerst de beide definities naast elkander plaatsen.

\section{Steenbergen}

Automatisering is de consequente toepassing van het stroomprincipe in het produktieproces, dat, in evenwicht gehouden door terugkoppelingssystemen en steunend op een integrale elektronische informatieverwerking, is afgestemd op een bepaald patroon in de afzet (p. 14).

\section{Bosch}

Een proces is geautomeerd wanneer het wordt uitgevoerd door machines, welke bestuurd worden door apparatuur, die op basis van in het geheugen vastgelegde werkinstructies de uit het proces en/of van buiten afkomstige informaties verwerkt en beslissingen neemt, die het verloop en/of de uitkomst van het proces overwegend of geheel bepalen (p. 31).

Afgezien van het verschil in terminologie, is er een duidelijk verschil tussen de overwegend instrumentele benadering van Bosch en de overwegend organisatorische benadering van 
Steenbergen. Het is daarbij opmerkelijk dat de laatste behoefte heeft gevoeld het instrumentele aspect toch tot uiting te brengen, doch alleen in de administratieve sector: "Steunend op een integrale elektronische informatieverwerking".

De definitie van Steenbergen suggereert dat de consequente toepassing van het stroomprincipe, althans bij een ,betrekkelijk stabiele en voorspelbare markt" (p. 15) steeds gewenst, althans mogelijk is. De definitie van Bosch stelt alleen maar vast onder welke omstandigheden van een "geautomeerd proces" kan worden gesproken.

Legt Steenbergen geen verdere beperkingen aan omtrent het toepassingsgebied van de automatisering, Bosch behandelt (op p. 40 $\mathrm{t} / \mathrm{m} 47$ van zijn boek) drie categorieën van bedrijven die resp. voor volledige, voor gedeeltelijke en voor zeer geringe mate van automering in aanmerking komen. Hierbij komt het begrip stroomproduktie eveneens aan de orde.

Het is om deze en soortgelijke redenen ten zeerste aan te bevelen beide studies gemeenschappelijk te bestuderen. Zij vullen elkaar meer aan dan dat zij elkaar 7.ouden tegenspreken.

De studic van Steenbergen is verdeeld in 3 delen. Het eerste deel is algemeen oriënterend en methodologisch. Het tweede behandelt de invloed van de automatisering op de leiding van en de staffuncties in het bedrijf. Het derde bespreekt de problemen van de arbeider.

De schrijver heeft zijn stof ontleend aan waarnemingen en gesprekken gedurende een studiereis van 16 maanden in de Verenigde Staten van Noord-Amerika, alsmede uiteraard aan literatuur, waarvan een uitgebreide bibliografie met zorgvuldig en volledig omschreven titels is opgenomen.

Steenbergen vestigt in zijn inleiding de aandacht op twee beperkingen:

a. de studie beoogt geen volledig beeld te geven van de invloed van de automatisering op het bedrijf;

b. de studie is bepcrkt tot de Verenigde Staten.

Beide beperkingen zijn nader gemotiveerd.

Het eerste hoofdstuk, onder de titel „Automatisering: van technologie tot methodologie", geeft een beknopte inleiding tot de begrippen automatisering, terugkoppeling, digitale en analoge computers. Bij de begripsbepaling van automatisering is sterk de aan- dacht gericht op het technische produktieproces en in het bijzonder de homogene en heterogene massaproduktie. Aan de mogelijkheden van toepassing van automatisering in handels- en dienstenverlenende bedrijven wordt vrijwel voorbijgegaan, de automatisering van de informatieverwerking (de administratie) wordt uitsluitend gezien als voorwaarde voor de automatisering van het produktieproces, niet als een zelfstandig probleem met eigen technieken en desiderata. Mede hierdoor komt het tegenkoppelingseffect van de administratie niet tot uiting (men zie ook de definitie, waar terugkoppelingssystemen en informatieverwerking naast elkaar worden gesteld en waarin niet tot uiting komt dat de informatieverwerking voor een belangrijk deel de functie van een terugkoppelingssysteem vervult).

Uitvoerig wordt aandacht besteed aan het „Mechanization profile" van J. R. Bright, dat ook aan kritiek wordt onderworpen.

Schrijver besluit dit hoofdstuk met een speculatie over de ontwikkeling van de technologische aspecten der automatisering. In het laatste stadium van de ontwikkeling wordt een overgang voorzien naar het volautomatische bedrijf dat de lijnen tussen de bedrijfstakken zal doen vervagen doordat de machines voor meervoudige doeleinden geschikt zullen zijn (p. 21).

Het tweede hoofdstuk behandelt meer expliciet de automatisering van het produktieproces. Een viertal voorwaarden voor automatisering wordt genoemd, waarbij het niet duidelijk is of aan al deze voorwaarden moet worden voldaan of dat het bestaan van één voorwaarde al voldoende wordt geacht. Overwogen wordt of automatisering partieel of integraal moet worden ingevoerd, waarbij de voorkeur uitgaat naar een integrale toepassing. Indien de nadelen daarvan overheersen, is in ieder geval een integrale planning van de automatisering nodig.

Het hoofdstuk eindigt met een beschouwing over de flexibiliteit, waarbij ook een aantal mogelijkheden om aanpassing aan de zijde van de afzetmarkt te bereiken wordt behandeld.

In hoofdstuk III wordt de automatisering van de informatieverwerking besproken.

$\mathrm{Na}$ een korte bespreking van het begrippenarsenaal volgt een opsomming van een aantal knelpunten in het administratieve proces die tot elektronische informatieverwerking kunnen initiëren. Deze opsomming vat zeer heterogene kwesties in één lijst samen ( $p$. $40 / 1)$. 
Een behandeling van de vraag Partiële of integrale elektronische informaticverwerking leidt tot voorkeur voor de integrale aanpak. Hoewel men het met deze conclusie eens kan zijn, komen de aangevoerde argumenten weinig overtuigend voor. De argumenten zijn: praktijkervaring, mogelijke verbetering van procedures door integrale aanpak, gevaar van een beperkte doelstelling die onverenigbaar kan zijn met de algemene bedrijfsdoeleinden (bewezen uit een voorbeeld dat niet geheel ter zake is) en het "beter naar voren brengen" van de verschillende mogelijkheden van de computer (p. 42/3).

Het komt mij voor dat het laatste, wat terloops behandelde argument, het zwaarste had behoren te wegen en meer gedetailleerde behandeling had verdiend. Eerst de integrale aanpak geeft de gelegenheid in voldoende mate gebruik te maken van de vele mogelijkheden die de kostbare automatisering biedt. Schrijver waarschuwt tegen instelling van rekencentra (p. 44). Het zou interessant zijn geweest indien hicr praktijkervaringen konden zijn ingevoegd.

$\mathrm{Bij}$ de besprcking van de mogelijkheden van de computer komen vooral psychologische aspecten aan de orde. De "oude garde" wordt gesteld tegenover de ,militante jonge computer-men" (p. 45). In de paragraaf over ouderdom, kosten en waarde van informatie onderscheidt Steenbergen twee facetten van "ouderdom":

a. het informatie-interval (van een andere zijde beschouwd: de frequentie waarmee een bepaalde soort informatic wordt verstrekt);

b. de informatic-vertraging (periode tussen einde van het interval en het moment dat de informatie beschikbaar is) (p. 47).

Schrijver stelt dat er aanwijzingen zijn dat de kosten van informatie (per verwerkt basis-element) omgekeerd evenredig zijn aan de tijdslengte van het gekozen interval. Deze uitspraak is niet geargumenteerd en men zou benieuwd zijn wélke aanwijzingen het hier betref $t$. Bovendien lijkt het belangrijk om na te gaan of deze vuistregel door automatisering, vooral met behulp van de moderne random-access-apparatuur, wordt gemodificeerd.

De volgende paragraaf behandelt informatiestructuur en informatiebehoefte. Het onbevredigende van de term ,systeemanalist" komt duidelijk tot uiting in de uitspraak "Het werk van de systeemanalist is creatief" (p. 52). Creatie door analyse lijkt mij een terminologische tegenspraak.
Op p. 53 wordt gesteld dat de gestandaar. diseerde machineprogramma's die enkele computer-fabrikanten hebben ontworpen voor bepaalde bedrijfstakken, de programmeerarbeid vereenvoudigen en slechts hier en daar passend gemaakt behoeven te worden voor de specifieke behoeften van de a.fzonderlijke bedrijven.

Dit lijkt mij in strijd met schrijvers voorkeur voor een integrale aanpak van de automatisering van de informatieverwerking. De ervaring leert dat elk bedrijf een unieke entiteit is; factoren als vestigingsplaats, voorgeschiedenis, mentaliteit van de hoogste leiding hebben belangrijke invloed op een bedrijf, veelal meer dan de aard van de geproduceerde artikelen. Een integrale aanpak zal met deze invloedsfactoren ten volle rekening moeten houden; dit eist meer dan een „passend maken" van confectie-programma's. Wel is uiteraard veel nut te verwachten van deelprogramma's, die een bepaald, frequent voorkomend deelprobleem in de informatieverwerking oplossen, en die op verschillende wijze in cen geïntegreerd systeem kunnen worden ingepast. De grenzen van de toepasbaarheid van deze deel-programma's vallen in het geheel niet samen met de grenzen der bedrijfstakken.

Het tweede en derde deel van het boek behandelen de interne organisatie. De aanpak is, met schrijvers eigen woorden, minder gericht op de structurele, dan op de persoonlijke aspecten van de organisatie. Centraal wordt het "rolbegrip" gesteld. Deze wijze van aanpak brengt de behandeling van het bedrijfseconomische naar het bedrijfssociologische en -psychologische terrein. Ik beb op dit gebied onvoldoende deskundigheid om daarover een oordeel te kunnen uitspreken.

Veel van wat is gegeven is voor de bedrijfseconomisch geschoolde interessant; aangezien hij niet of te weinig op de hoogte is van andere benaderingswijzen, kan hij de directe waarde van schrijvers uitspraken niet toetsen.

Enkele van de uitspraken verdienen hier gememoreerd te worden.

- Praktisch elke rol (in de zin van positie in een bedrijf) echter heeft een mengsel van economische en niet-economische beloningen nodig: hoe hoger de eerste, des te lager kan de andere zijn en vice-versa (p. 65). Dit komt in strijd met de feiten: het is niet zo dat een hoog salaris gewoonlijk gepaard gaat met een lage status en een gering prestige of omgekeerd. Eerder 
zou gesteld moeten worden dat een zeker evenwicht tussen beide soorten van beloningen gehandhaafd moet blijven (Dit ligt buiten het bedrijf, en vooral in de concurrentie tussen bedrijven, overheid en wetenschap anders!).

- De automatisering van het bedrijf gaat gepaard met een toenemende gecompliceerdheid van techniek, logistiek en marktonderzoek en een groter worden van het ondernemersrisico (p. 70). Node mist men hier de adstructie die althans tot een begin van bewijs en tot onderkennen van de economische consequenties had kunnen leiden.

- Zoals „scientific management” de arbeider de planning van zijn werk ontzegde, en die aan een hogere geleding in de bedrijfshiërarchie toevoegde, zo zijn er aanwijzingen dat automatisering de resterende planning aan de subalterne leiding zal ontnemen en deze naar de hoge staffuncties zal overhevelen (p. 76).

De subalterne leiding ontleende zijn status en prestige voor een belangrijk deel aan dergelijke (d.w.z. op ervaring steunende) decisies, die in wezen routinebeslissingen zijn die geprogrammeerd en door de computer overgenomen kunnen worden (p. 76).

Dit sombere vooruitzicht voor het instituut van "subalterne leiding": haar taak vervalt, haar positie wordt ondergraven, wordr gelukkig verguld door hetgeen op p. 80 is opgemerkt: Deze strategische decisies moeten door de lagere rangen worden uitgevoerd en hier begint de taak van de subalterne leiding. Wat begon als algemene directieve moet door de subalterne leiding toegespitst worden tot specifieke orders en communicaties.

- De capaciteit van de computer noopt tot centralisatie van de informatieverwerking (p. 93).

De ontwikkeling gaat bepaald niet uitsluitend in de richting van centralisatie. Blijkbaar is de vraag naar informatieverwerkende apparatuur die de mogelijkheid tot decentralisatie biedt, zo groot, dat verscheidene fabrikanten dergelijke apparatuur aanbieden en in ontwikkeling hebben. $W_{i j}$ dienen hierbij uiteraard onderscheid te maken tussen de geografische en de functionele decentralisatie. Ook een geografisch centraal opgestelde informatieverwerkingsapparatuur $k a n$ in principe functioneel volledig gedecentraliseerd worden gehanteerd, mits de daarvoor nodige contactorganen en communicatiekanalen ter beschikking zijn.

- Door de starheid van de produktie lijkt het waarschijnlijk dat niet meer de verkoop de produktie zal decreteren, doch dat het omgekeerde zal geschieden (p. 94). Een ietwat beangstigende voorspelling, want slechts een stapje verder en de consument móet aanschaffen wat de automatische monsters produceren; centrale leiding kan dan niet meer worden gemist. Voorlopig houd ik het er maar op dat de verkoop er wel in zal slagen de bedrijfsleiding te overtuigen dat de produktie dan maar minder star moet worden n'en déplaise de ,eisen" van de machines.

- Het moreel van de machinebediende heeft geen enkel effect op de produktiviteit van de (automatische) machines waarop hij toezicht moet houden (p. 141). De hierachter schuilende gedachtengang is moeilijk te volgen. Indien een toezicht nodig is, dan betekent dat, dat op zekere momenten van de toezichthouder een handeling wordt verwacht. Achterwege blijven van die handeling verstoort op een of andere wijze de produktie (soms in belangrijke mate). Indien onvoldoende moreel leidt tot bv. onverschilligheid bij de toezichthouder, zal de handeling gemakkelijker achterwege blijven of te laat komen, dan in het tegenovergestelde geval.

De studie van Steenbergen thans overziende meen ik dat zij een verfrissende behandeling geeft van enkele gevolgen van de automatisering voor het bedrijf. De beperkingen zijn door de schrijver expliciet gesteld en men doet goed die bij lezing in het oog te houden.

De waarde van de studie schuilt vooral in het openen van een gezichtsveld. Het gezichtsveld namelijk van de centrale plaats die de mens en de intermenselijke verhoudingen in her bedrijf, zoals in elke organisatie innemen. Dat dit op een eigen wijze is gedaan, die wel eens tot tegenspraak prikkelt, resp. waaromtrent de aangevoerde argumenten zwakker zijn dan nodig leek, doet aan de waardering die uit het voorgaande spreekt niet af. Het belangrijkste hoofdstuk voor ieder die invoering van automatisering van de produktie, doch vooral van de informatieverwerking overweegt, lijkt mij hoofdstuk VI van deel III:

Weerstanden tegen veranderingen in het bedrijf (p. 143 e.v.). De hier gegeven overwegingen zijn van direct praktisch belang. 